\title{
Impact of residential wood combustion on ambient air quality
}

\author{
A.-M. Carter ${ }^{1}$, A. Germain ${ }^{1}$, J. Rousseau ${ }^{2}$, M. Bisson ${ }^{3}$ \\ \& C. Gagnon ${ }^{4}$ \\ ${ }^{I}$ Environment Canada, Environmental Protection Branch, Canada \\ ${ }^{2}$ Environment Canada, Meteorological Services of Canada, Canada \\ ${ }^{3}$ Ministère de l'Environnement du Québec, Canada \\ ${ }^{4}$ City of Montreal, Canada
}

\begin{abstract}
Wood heating provides $12 \%$ of the energy needs to heat Canadian homes and was identified as one of the main sources of air pollution in urban areas. A sampling station was established in order to evaluate the impact of wood heating on ambient air in a residential area of Montreal and the results were compared to those measured in downtown Montreal. In the residential area, fine particulates $\left(\mathrm{PM}_{2.5}\right)$, polycyclic aromatic hydrocarbons $(\mathrm{PAHs})$ and dioxin and furan $(\mathrm{D} / \mathrm{F})$ levels were respectively $10 \%, 85 \%$ and $68 \%$ higher than those measured in downtown Montreal during winter. Potassium (K) values were $40 \%$ greater in the $\mathrm{PM}_{2.5}$ samples collected in the residential area than those from downtown in winter. For volatile organic compounds (VOCs), no statistical differences were observed between the two locations in winter but the presence of certain VOCs at levels similar to those measured downtown is probably caused by wood combustion in the residential area. $\mathrm{PM}_{2.5}, \mathrm{PAHs}, \mathrm{D} / \mathrm{F}$ and $\mathrm{K}$ winter values can be up to five times greater than those from summer in the residential area while seasonal differences in downtown vary only by a factor of up to two. For VOCs, seasonal differences exist for many of the compounds measured. Between 1998 and 2002 the seasonal differences in pollutant concentrations vary more in the residential area than in downtown. This indicates that wood combustion contributes to the deterioration of ambient air quality.
\end{abstract}

Keywords: home heating, wood combustion, PAHs, VOCs, dioxin/furan, residential area, downtown. 


\section{Introduction}

In 2000 , the energy demand for the residential sector totalled 1,388 petajoules (PJ) in Canada and about $60 \%$ of this energy was used for home heating [1]. Natural gas represented the largest source with $55 \%$ of the energy used to heat Canadian homes and wood provided $12 \%$ of the needs. However, residential wood combustion is an important source of pollution and it is responsible for $29 \%$ of the emissions of fine particulate $\left(\mathrm{PM}_{2.5}\right)$ when we exclude the open sources such as forest fires and dust from paved and unpaved roads [2]. A study conducted in 1998 identified residential wood heating as one of the main sources of air pollution in the Greater Montreal area [3]. In a review of the health impact of biomass combustion, Brauer [4] reported that exposure to biomass smoke indicates a consistent relationship between exposure and increased respiratory problems.

During the winter of 1999, samples taken from a monitoring station located in Rivière-des-Prairies (RDP) showed that the concentrations of several pollutants were greater in this residential area than in downtown Montreal [5]. Furthermore, a survey conducted in 2000 confirmed that this residential district, located northeast of Montreal, is among the sectors of the island where an important number of homes are heated by wood as a primary or secondary heating system [6].

The present study compares air pollutant values obtained between December 1998 and May 2002, in downtown Montreal with values measured in RDP, a residential area where residential wood combustion is popular. It also assesses the impact of residential wood combustion to these measured differences.

\section{Methodology}

The RDP residential area is located in the northeast section of the City of Montreal. The sampling site is mainly surrounded by single-family homes or duplex housing units built 15 to 20 years ago, and represents a high density of wood heating systems [6]. This site is only slightly influenced by motor vehicle traffic and no industrial facilities are located nearby. The reference station used in this project is located on Ontario Street, close to Montreal's downtown area, and is mostly influenced by motor vehicle traffic.

Samples were taken and analysed for polycyclic aromatic hydrocarbons $(\mathrm{PAH})$, dioxins and furans $(\mathrm{D} / \mathrm{F})$, volatile organic compounds (VOC), fine particulate matter $\left(\mathrm{PM}_{2.5}\right)$, and metals. The sampling was done according to the National Air Pollution Surveillance (NAPS) Network schedule, e.g. one sample every 6 days for PAHs, D/F, VOC and metals; $\mathrm{PM}_{2.5}$ was measured continuously with a Tapered Element Oscillating Balance (TEOM) analyzer and PAHs were also measured continuously at the RDP site with a real-time PAH Analyzer, using a Photoelectric Aerosol Sensor (PAS). Its principle of operation is based on the photo ionization of carbon aerosols [7]. It was calibrated with the results obtained from the air samples taken with the high volume sampler that collected both particulate (on a filter) and gaseous (on a polyurethane foam) PAHs. 
PAHs, D/F, VOCs and metal analyses were done by Environment Canada's Environmental Technology Center according to their standardized procedures. Statistical treatment of data was carried out using the Statgraphics ${ }^{\circledR}$ Plus software for Windows ${ }^{\circledR}$.

\section{Results}

\subsection{Polycyclic aromatic hydrocarbons}

During the four winters for which data were collected, the mean daily concentration of polycyclic aromatic hydrocarbons (PAHs) measured in the area influenced by residential wood combustion was $74.6 \mathrm{ng} / \mathrm{m}^{3}$. This concentration is five times greater than the concentration measured in summer, and twice the concentration measured in the downtown area in winter, (Figure 1). At the residential site, the highest monthly values occurred from November to February, reaching a peak in January.

The seasonal variations were much more pronounced in the residential area than in downtown Montreal. This is an indication that the sources of PAHs were present throughout the year in the downtown area, while in the residential area, an important source of PAHs was present only in winter. Motor vehicle traffic explains the relatively constant concentrations found in the downtown area, while wood combustion may explain the important fluctuations noted between winter and summer in the residential area.

\section{Seasonal Variation of PAHs}

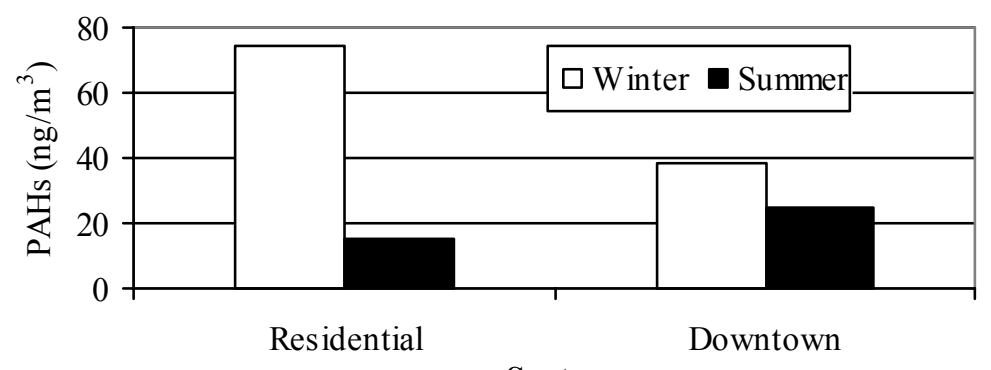

Sector

Figure 1: Seasonal variation of PAHs in the Residential Area and in downtown Montreal.

PAHs were also measured using a continuous analyzer in the residential sector influenced by wood combustion. The highest mean hourly value $\left(144 \mathrm{ng} / \mathrm{m}^{3}\right)$ occurred during the evening on weekends in winter. This value was $30 \%$ higher than on weekday evenings in winter, and 10 times higher than during the evening in summer (Figure 2). 
Hourly Variation of PAHs in the Residential Area

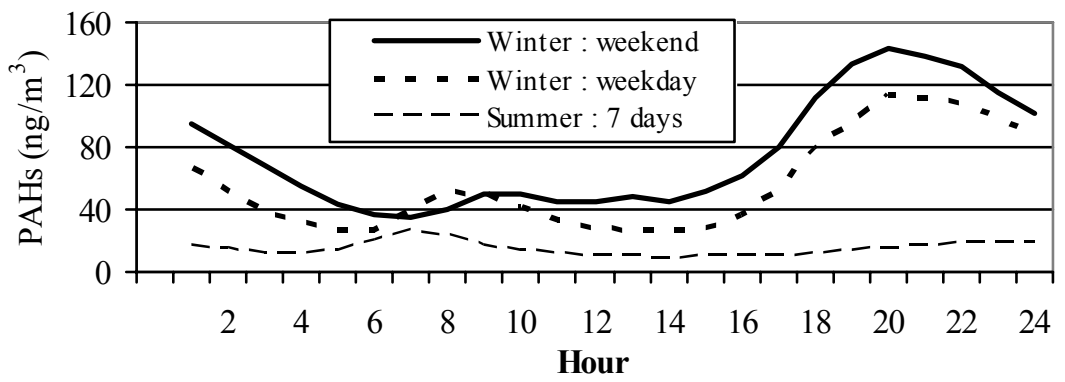

Figure 2: Hourly variation of PAHs measured with a real-time instrument in the residential area influenced by wood heating.

\subsection{Dioxins and furans}

Among the dioxins and furans (D/F) emitted during wood combustion, seventeen compounds are of particular concern as regards to their impact on human health. Their concentrations are expressed in terms of toxicity equivalent (TEQ) as compared to the most toxic product of the group, that is $2,3,7,8$-TCDD. In the residential area, the mean TEQ concentration was 2.5 times greater in winter $\left(0.069 \mathrm{pg} \mathrm{TEQ} / \mathrm{m}^{3}\right)$ than in summer $\left(0.028 \mathrm{pg} \mathrm{TEQ} / \mathrm{m}^{3}\right)$ and 1.7 times greater than in downtown Montreal in winter $\left(0.041 \mathrm{pg} \mathrm{TEQ} / \mathrm{m}^{3}\right)$ as shown in Figure 3.

On an annual basis, the mean TEQ concentration in 2001 was $0.049 \mathrm{pg} / \mathrm{m}^{3}$ in the residential area, and $0.031 \mathrm{pg} / \mathrm{m}^{3}$ in the downtown area. In both cases, the concentrations are below the annual criteria established at $0.060 \mathrm{pg} / \mathrm{m}^{3}$ by the Ministère de l'Environnement du Québec [8].

Seasonal Variation of Dioxins and Furans

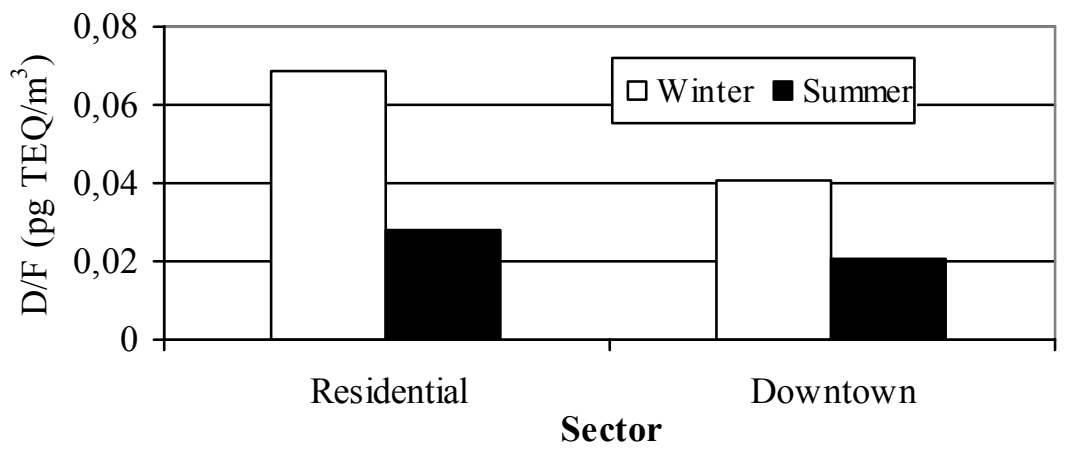

Figure 3: Seasonal variation of dioxins and furans measured in the residential area and in downtown Montreal. 


\subsection{Volatile organic compounds}

Compared to the winter of 1999 , we did not find any significant differences in the concentrations of VOCs measured in the residential area and in downtown Montreal for the whole project. However, the presence of certain VOCs at levels similar to those measured downtown is probably caused by wood combustion in the residential area, since motor vehicle traffic, the major source of VOCs, is not important in this sector.

More specifically, non-polar VOCs, such as alkanes, halogens and aromatics, do not follow seasonal trends, with the exception of the alkene/alkyne group. A few of the alkene/alkynes such as 1,3-butadiene, ethylene and acetylene, were present in greater concentrations in winter than in summer.

Excluding formaldehyde, total polar VOCs showed a seasonal trend and concentrations were greater in winter than in summer in the residential area. However, the concentrations remained lower than those recorded at the downtown site. The same trend was noted for certain individual substances such as methyl ethyl ketone/butyraldehyde, acetaldehyde, acrolein and benzaldehyde.

\subsection{Fine particulates}

In winter, daily concentrations of particulate matter $\left(\mathrm{PM}_{2.5}\right)$ were $10 \%$ greater in the residential area $\left(10.1 \mu \mathrm{g} / \mathrm{m}^{3}\right)$ than in downtown Montreal $\left(9.2 \mu \mathrm{g} / \mathrm{m}^{3}\right)$ and were also $10 \%$ greater than in summer in the residential area. When only the evening levels of $\mathrm{PM}_{2.5}$ are taken into account (from 6 p.m. to midnight), the difference between concentrations measured in the residential area $\left(13.9 \mu \mathrm{g} / \mathrm{m}^{3}\right)$ and in downtown Montreal $\left(11.0 \mu \mathrm{g} / \mathrm{m}^{3}\right)$ reached $25 \%$ in winter (Figure 4). Lastly, $\mathrm{PM}_{2.5}$ concentrations measured in the residential district in winter were $60 \%$ greater than the concentrations measured on summer evenings.

Similar to PAHs, $\mathrm{PM}_{2.5}$ concentrations were greater on winter weekend evenings. Hourly average concentrations reached $17.9 \mu \mathrm{g} / \mathrm{m}^{3}$, while they were only $14.6 \mu \mathrm{g} / \mathrm{m}^{3}$ during weekdays. No such difference was noted in summer, either during the day or at night (Figure 5).

Seasonal Variation of $\mathrm{PM}_{2.5}$

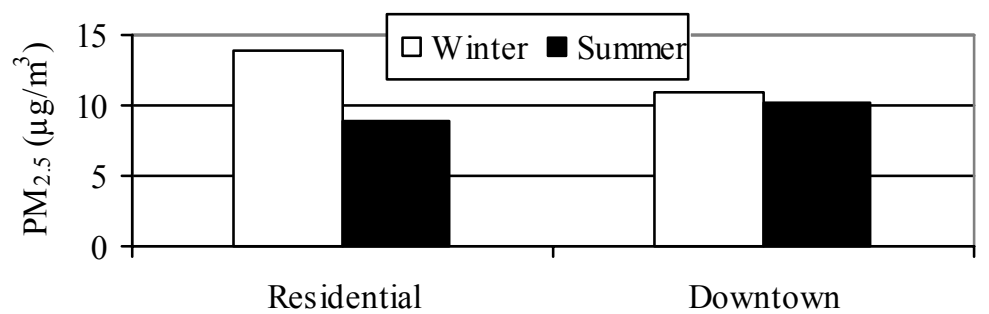

Sector

Figure 4: Seasonal variation of $\mathrm{PM}_{2.5}$ measured in evenings in the residential area and in downtown Montreal. 


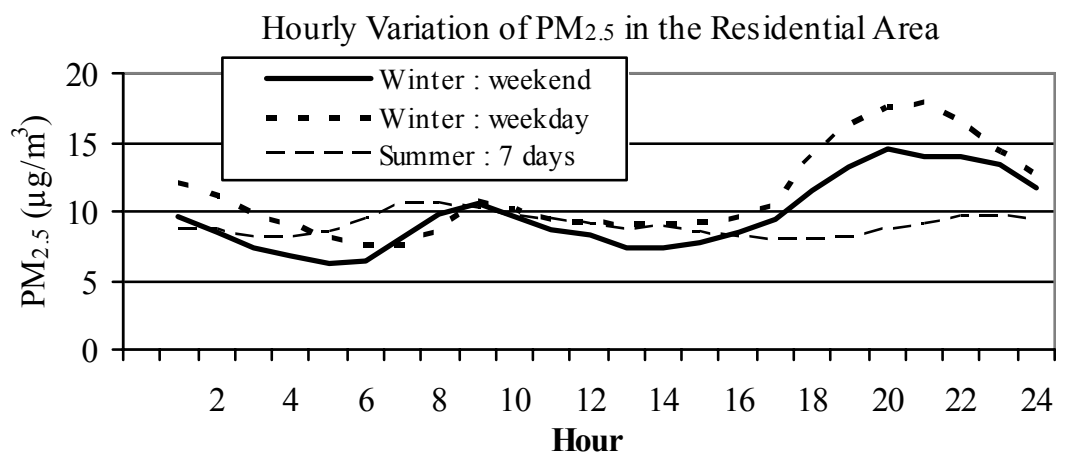

Figure 5: Hourly variation of $\mathrm{PM}_{2.5}$ measured in the residential area influenced by wood heating.

\subsection{Metals}

Among all the metals measured, the presence of $\mathrm{K}$ and the relationship of $\mathrm{K}$ to iron ( $\mathrm{Fe})$ are recognized as tracers for residential wood combustion [9]. The concentrations of $\mathrm{K}$ measured in the residential sector in winter $\left(0.13 \mu \mathrm{g} / \mathrm{m}^{3}\right)$ were $150 \%$ greater than those measured at the same site in the summer, and $40 \%$ greater than those measured downtown in winter. The high $\mathrm{K}$ to $\mathrm{Fe}$ ratio $(\mathrm{K} / \mathrm{Fe})$ provided an indication of the presence of residential wood combustion. In the residential sector, this ratio was $200 \%$ higher in winter (3.6) than in summer, and $80 \%$ higher than in the downtown area in winter, fig. 6 .

\section{Seasonal Variation of $\mathrm{K} / \mathrm{Fe}$}

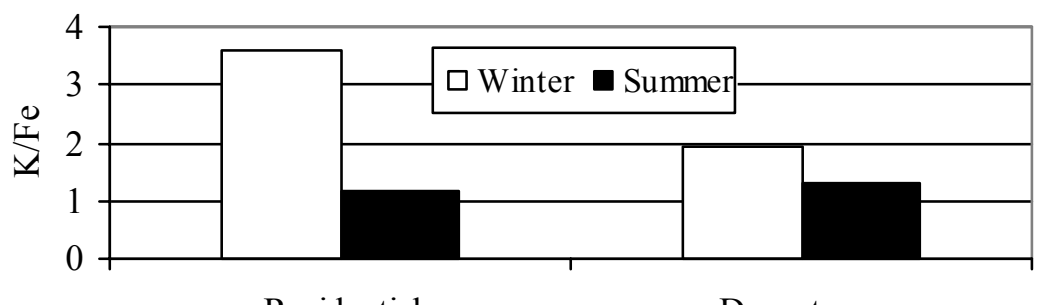

Sector

Figure 6: $\quad$ Seasonal variation of $\mathrm{K} / \mathrm{Fe}$ ratio calculated with metal values from the residential area and from downtown Montreal.

\section{Conclusions}

Results obtained between 1999 and 2002 in a residential area of Montreal where wood is a significant heating fuel, indicate that wood combustion contributes to 
the deterioration of ambient air quality. Concentrations of some pollutants can be five times higher in winter than in summer. When the residential area influenced by wood combustion is compared to the downtown area, winter concentrations of $\mathrm{PM}_{2.5}$ and PAHs can be twice as high.

\section{References}

[1] Natural Resources of Canada. End-Use Energy Data Handbook: 1990 to 2000. Office of Energy Efficiency, Ottawa. 110 p.

[2] Niemi, D. Personal communication, 29 October 2004, Environment Canada, Pollution Data Branch, Ottawa, Canada.

[3] Regroupement montréalais pour la qualité de l'air (RMQA), 1998, Pollution atmosphérique et impacts sur la santé et l'environnement dans la grande région de Montréal, Montréal, $356 \mathrm{p}$.

[4] Brauer M. Health impacts of biomass air pollution. Report prepared for the WHO biregional workshop on health impacts of haze-related air pollution. Kuala Lumpur, Malaysia, 1-4 June 1998.

[5] Bonvalot Y., Gagnon, C., Benjamin M., Germain A. \& Dann T., Sampling Program for Residential Wood Combustion: Winter of 1998-99 Study Report, Public Works and Government Services Canada, Ottawa, 2000,80p.

[6] Labrèche F., Bonvalot, Y. \& Boivin M.-C., Enquête téléphonique sur la possession et l'acquisition d'un système de chauffage au bois dans la région de Montréal, Direction de la santé publique, Régie régionale de la santé et des services sociaux de Montréal-Centre, Montréal, 2000, 54 p.

[7] Chikhliwalw, E.D., J.W. Podlenski, E. Pfeiffer \& W. Siefert The Design, Implementation and Use of a Real-Time PAH Analyzer for Combustion Products. Proc. of the 9th World Clean Air Congress, ed. Air \& Waste Management Association, Pittsburg, paper IU-13C.07, 1992.

[8] Critères de qualité de l'air. Fiches synthèses. Gouvernement du Québec, Ministère de l'Environnement, Direction du suivi de l'état de l'environnement, http:/www.menv.gouv.qc.ca/air/criteres/fiches.pdf.

[9] Lewis, C.W., Baumgardner, R.E. \& Stevens, R.K., Contribution of Woodsmoke and Motor Vehicle Emissions to Ambient Aerosol Mutagenicity, Environm. Sci. Technol. 22, 968-971, 1988. 